\title{
O USO DE DIFERENTES ESPAÇOS ESCOLARES NAS AULAS DE CIÊNCIAS DA NATUREZA
}

Kely Cristina Bueno ${ }^{1}$

(iD) https://orcid.org/0000-0001-8884-5208

Fernanda Franzolin ${ }^{2}$

(iD) https://orcid.org/0000-0001-8808-9107

Resumo: 0 espaço escolar não é constituído apenas por salas de aulas convencionais. $\hat{E}$ objetivo deste artigo, verificar diante da disponibilidade dos espaços escolares a respectiva frequência de utilização para o ensino de Ciências pelos professores de escolas públicas dos Anos Iniciais do Ensino Fundamental. Trata-se de uma pesquisa qualitativa, por utilizar o critério da máxima variação para seleção de escolas com diferentes perfis. A coleta de dados realizou-se através de questionário e a análise, por meio de estatística descritiva. Os resultados indicam que os locais mencionados como mais usados pelos docentes são: a sala de informática e a biblioteca. Entre os espaços menos mencionados estão os espaços verdes e os laboratórios de ciências.

Palavras-chave: Espaços formais de ensino. Prática escolar. Ensino de ciências. Anos iniciais do ensino fundamental.

\footnotetext{
1 Doutoranda pela Universidade de São Paulo. E-mail: kelybueno.kcb@usp.br

${ }^{2}$ Doutora em Educação pela Universidade de São Paulo. Professora Universidade Federal do ABC. E-mail: fernanda.franzolin@ufabc.edu.br
} 


\title{
THE USE OF DIFFERENT SPACES IN THE CLASSES NATURAL SCIENCES
}

\begin{abstract}
The school space does not of consist only conventional classrooms. It is the objective of this article to verify the frequency of use of different spaces for teaching science by public school teachers of Elementary School, in view of the availability of school spaces. The study refers to a qualitative research, taking into account the criterion of maximum variation for the selection of schools with different profiles. The data were collected through a questionnaire and the analysis, through descriptive statistics. The results indicate that the places mentioned as being most used by teachers are: the computer room and the library. Among the less mentioned spaces are the spaces green spaces and science laboratories.
\end{abstract}

Keywords: Formal spaces of teaching. School practice. Teaching of natural sciences. Elementary education.

\section{EL USO DE DIFERENTES ESPACIOS ESCOLARES EN CLASES DE CIENCIAS NATURALES}

Resumen: El espacio escolar no se compone solo de aulas convencionales. El objetivo de este artículo es verificar, en vista de la disponibilidad de espacios escolares, la frecuencia respectiva de uso para la enseñanza de las ciencias por parte de los maestros de las escuelas públicas de la educación primaria. Es una investigación cualitativa, ya que utiliza el criterio de máxima variación para seleccionar escuelas con diferentes perfiles. La recolección de datos se realizó a través de un cuestionario y el análisis, utilizando estadísticas descriptivas. Los resultados indican que los lugares mencionados como los más utilizados por los maestros son: la sala de computadoras y la biblioteca. Entre los espacios menos mencionados se encuentran los espacios verdes y los laboratorios de ciencias.

Palabras clave: Espacios de ensenãnza formal. Práctica escolar. Enseñanza de las ciências. Educación primaria. 


\section{Introdução}

Os espaços formais de ensino, onde a educação é formalizada, garantida por lei de acordo com a padronização nacional, é constituído por dependências como sala de aula, laboratório, quadras de esporte, bibliotecas, entre outros (JACOBUCCI, 2008). As escolas brasileiras podem dispor de diferentes estruturas a serem utilizadas auxiliando no processo de ensino e aprendizagem dos alunos. Para promover essa interação é importante proporcionar um ambiente físico que estimule e viabilize a aprendizagem, além de favorecer as interações humanas (SOARES NETO et al., 2013a).

Para Moran (2004), a sala de aula constitui um ambiente importante de aprendizagem, mas é preciso combinar outros espaços para ampliar as possibilidades de atividades. Segundo Nakamura, Bernardi e Lamim-Guedes (2012), alguns espaços escolares podem se tornar ferramentas didático-pedagógicas fabulosas para desenvolver trabalhos como o de educação ambiental envolvendo problemáticas socioambientais que emergem da sociedade moderna e também permitem relacionar homem-natureza, possibilitando uma abordagem mais contextualizada dos conteúdos curriculares.

Para o ensino de Ciências, a literatura apresenta uma gama maior de trabalhos focados em espaços não formais de ensino, como museus, zoológicos e jardim botânico. Entretanto, no que se refere à utilização de espaços escolares diferenciados, há uma carência de trabalhos que retratam sua utilização pelos professores. Neste trabalho, abrangeremos espaços como biblioteca, sala de informática, laboratório de Ciências, hortas ou espaço para plantio, jardim e espaço com árvores.

Este artigo tem por objetivo investigar, diante da disponibilidade, a frequência e a variação na utilização de diferentes espaços escolares de aprendizagem, além da sala de aula convencional, usados por professores dos Anos Iniciais do Ensino Fundamental, nas aulas de Ciências da Natureza. Esta pesquisa foi desenvolvida para a dissertação de mestrado da Universidade Federal do $A B C$, no qual também procurou investigar os recursos e procedimentos didáticos também usados por estes professores.

\section{A infraestrutura das escolas brasileiras}

De acordo com Nóvoa (2011), o funcionamento da organização escolar é um compromisso entre estrutura formal e as interações que se produzem, determinadas 
através de três grandes áreas, sendo elas a estrutura física, administrativa e social. Todas as categorias têm sua importância para o bom desempenho da escola, porém, há de se destacar neste trabalho a primeira. A estrutura física da escola comporta a dimensão e edifício escolar, organização da escola, materiais didáticos, entre outros.

A infraestrutura e recursos pedagógicos são compreendidos por materiais didáticos disponíveis na escola, como prédios, equipamentos, livros didáticos, entre outros; sendo componentes fundamentais para o desempenho dos educandos (GOMES; REGIS, 2012; SOARES NETO et al., 2013b). De acordo com Sátyro e Soares (2007), a infraestrutura escolar pode exercer influência significativa na qualidade de ensino, assim, instalações adequadas, laboratórios, biblioteca escolar, bem como relação adequada entre o número de alunos e professor, possibilitam a melhoria do desempenho escolar.

De acordo com as notas estatísticas do Censo Escolar do ano de 2016 (INEP, 2017), 50,5\% das escolas de Educação Básica possuem biblioteca ou sala de leitura; sendo que $53,7 \%$ ofertam esse espaço de Ensino Fundamental. Nos Anos Iniciais, a biblioteca ou sala de leitura estão presentes em $49,2 \%$ das escolas e $79,1 \%$ dos matriculados em escolas urbanas têm acesso a esses espaços, comparado a 35,4\% dos matriculados em escolas da zona rural. Com relação ao laboratório de informática é possível afirmar que 44,7\% das escolas de Anos Iniciais do Ensino Fundamental possuem esse espaço e 68,2\% dos alunos matriculados têm acesso. Ademais, $76,5 \%$ dos alunos matriculados estudam em escolas que possuem computadores para seu uso e $85,9 \%$ destes educandos estudam em escolas conectadas à internet (tanto para o uso administrativo como para os alunos). Esse acesso é amplamente disponibilizado principalmente nas regiões Sul, Sudeste e Centro-oeste do país. As áreas verdes estão presentes em $27,5 \%$ das escolas e disponíveis a $37,5 \%$ dos matriculados que estudam nessas escolas nos Anos Iniciais do Ensino Fundamental. Ainda, 15,7\% dos matriculados possuem o Laboratório de Ciências como espaço disponível.

Nota-se que o suporte institucional é fundamental para que se possa desenvolver um bom trabalho educacional e que sem ele a atuação do professor deverá ser prejudicada (SOARES NETO et al., 2013b).

\section{Os diferentes espaços escolares para o ensino de Ciências}

Além da infraestrutura adequada e desenvolvimento de procedimentos diferenciados, é importante que o professor conheça e avalie os espaços de acordo com 
seu planejamento, adequando ao conteúdo a ser trabalhado, à quantidade de alunos e de materiais, equipamentos disponíveis nos locais e os objetivos a serem alcançados.

Nesta pesquisa abordaremos os seguintes ambientes escolares: biblioteca, laboratório de informática, laboratório de Ciências, espaços com árvores, jardins e hortas.

Entende-se como biblioteca escolar, espaços com instalações projetadas para reduzir barulhos e ser acessível às crianças, com mobiliário e acervo formado por diferentes tipos de materiais como: livros, periódicos, CDs, DVDs, entre outros; entretanto, há realidades onde funcionam em espaços adaptados ou pequenas salas. Dispõe de recursos educativos, integrado ao processo de ensino e aprendizagem, tendo como objetivo incentivar a leitura e conhecimento (GRAÇA; BERNARDES; SANTANA, 2007).

Nesta pesquisa, considera-se laboratório ou sala de informática como um espaço onde estão disponíveis computadores para uso dos alunos, propiciando diversas possibilidades de aprendizagem. Segundo Moran (2004), o professor pode utilizar o laboratório para organizar uma pesquisa, desenvolver atividades na internet, acompanhar práticas de projetos por meio de experiências que ligam o aluno à realidade, mostrar simulações virtuais, vídeos, materiais em CD e DVD, incentivar o uso de jogos, leitura de jornais online, entre outros.

O laboratório de Ciências constitui-se de um espaço destinado à realização de atividades experimentais. Segundo Hofstein e Lunetta (1982, 2004), o laboratório fornece um meio único de ensino e aprendizagem em Ciências, assim, pode ser considerado eficaz para a promoção do desenvolvimento de competências de manipulação, observação, compreensão de conceitos científicos e habilidades na resolução de problemas. Além disso, promove a competência de cooperação e comunicação entre os alunos.

A horta oferece diversas possibilidades na realização de atividades voltadas ao ensino de Ciências da Natureza, essencialmente relativa a relações ecológicas, além de constituir-se como um espaço onde os alunos trabalham de maneira espontânea e autônoma (WEISSMANN, 1998), promove educação ambiental (CRIBB, 2010), hábitos alimentares saudáveis (ARAÚJO; DRAGO, 2011), cultivo de hortaliças (REZENDE et al., 2014), entre outros.

Os jardins são considerados como espaços escolares com plantas de pequeno e médio porte, locais como bosques e grandes árvores. Os jardins escolares são considerados locais privilegiados para o trabalho com Educação Ambiental, podendo desenvolver problemáticas socioambientais. Esses locais permitem contextualizar os 
conteúdos curriculares e abordar a relação entre homem e natureza. Nesses espaços, podem-se presenciar espécies nativas e exóticas, invertebrados, fungos e, compreender relações ecológicas, associações de agentes polinizadores, entre outros (NAKAMURA; BERNARDI; LAMIM-GUEDES, 2012). É importante que as crianças tenham a oportunidade de vivenciar a natureza, estabelecendo conexões. Além disso, o espaço permite o registro fotográfico, a observação de árvores e plantas no meio ambiente local, a verificação das mudanças ocorridas e experimentação do mundo (WARD et al., 2010).

Portanto, uma educação científica restrita à sala de aula restringe a possibilidade de exploração e experimentação de diferentes espaços presentes em alguns ambientes escolares. Portanto, essa pesquisa busca conhecer o uso desses espaços pelos professores dos Anos Iniciais do Ensino Fundamental, nas aulas de Ciências da Natureza.

\section{Procedimentos metodológicos}

Apesar de esta pesquisa ter dados quantitativos, é considerada como qualitativa, devido à constituição da amostra. Utilizou-se o critério qualitativo da máxima variação, onde foram selecionadas poucas escolas, mas com diferentes características, procurando evitar vieses e encontrar padrões dentro de um grupo heterogêneo (PATTON, 1990). As escolas selecionadas pertencem a diferentes localidades do Brasil, com diferenciados Índices de Desenvolvimento da Educação Básica (Ideb) do ano de 2013. Além disso, adotou-se a amostragem por conveniência, considerando a possibilidade de coleta de dados na instituição de ensino em que a pesquisadora trabalhava.

Para a coleta de dados, foi elaborado um questionário composto por oito questões alternativas sobre uso de recursos, procedimentos didáticos e espaços escolares. Entretanto, neste artigo será considerada a pergunta sobre a utilização de espaços escolares, exceto a sala de aula convencional, para ministrar as aulas de Ciências da Natureza. As múltiplas opções de respostas para este questionamento abrangiam seis espaços escolares, sendo eles: a biblioteca, o laboratório de informática, o laboratório de Ciências, espaços com árvores, horta e jardins. Assim, para cada espaço, o respondente mencionava a opção de disponibilidade e assinalava frequência de utilização: "semanal”; "várias vezes dentro do bimestre", "eventual” ou "nunca”.

$\mathrm{Na}$ análise dos dados, as escolas participantes foram divididas em três grupos. 0 primeiro grupo (G1), foi formado por escolas com Ideb acima de 5.2, de diferentes localidades, sendo duas escolas no estado de São Paulo (município de São Bernardo do 
Campo) e uma na Bahia (Lauro de Freitas). 0 segundo grupo (G2), as escolas localizavamse em Pernambuco (Garanhuns), Bahia (Lauro de Freitas) e Minas Gerais (Belo Horizonte), todas com Ideb entre 4.5 e 5.1. 0 terceiro grupo (G3) constituiu-se por escolas de São Paulo (São Bernardo do Campo), Bahia (Lauro de Freitas) e Pernambuco (Garanhuns); ambas com Ideb inferior a 4.5 .

A constituição da amostra foi composta por nove escolas, sendo assim $\mathrm{N}=9$. Os professores respondentes totalizaram trinta e três, sendo assim representados por $n=33$. Estes lecionavam do $2^{\circ}$ e $5^{\circ}$ ano do Ensino Fundamental. Para a análise dos dados, levouse em consideração a disponibilidade dos espaços e a frequência de utilização. Assim, o n representa o número de participantes da amostra. 0 n' indica o número de participantes da amostra, excluindo aqueles que declararam não haver o espaço analisado na escola e o n" indica o número de professores que afirmam usar esses espaços. De tal modo, para cada gráfico ou tabela elaborados foram inseridos os valores amostrais de n' e n".

Para análise dos dados, utilizou-se de estatística descritiva. Para tanto, foram desenvolvidos índices. Deste modo, foram atribuídos valores diferenciados para cada alternativa de frequência de uso do espaço assinalada pelos professores: uso semanal = valor 3; uso várias vezes dentro do bimestre = valor 2; uso eventual = 0 valor 1; alternativa nunca, desconhece a disponibilidade do espaço, ou em branco = valor 0. Em seguida, foram realizadas somatórias dos valores atribuídos para cada espaço por todos os docentes e o total dividido por n'. Assim, obtivemos o que esta pesquisa denominou de Índice de Frequência de Utilização (IFU); que procurava expressar a frequência de utilização de cada espaço pelo grupo amostral total, envolvendo todos os participantes ou dentro de cada um dos grupos (Grupo 1, 2 e 3). Foram calculadas também, as medidas de dispersão (variância e o coeficiente de variação).

$\mathrm{Na}$ sequência realizou-se a análise da atuação individual dos professores respondentes. Para tal, primeiramente, considera-se a quantidade de espaços escolares cujos professores usavam para diversificar suas aulas. Sequencialmente, foi atribuído o valor 1 para cada espaço utilizado pelo professor (sala de informática, laboratório de Ciências, biblioteca, jardim, horta ou espaços com árvores). A somatória desses valores para cada professor foi organizada em categorias, sendo elas: 4-5, para alta variação; 3-2, para média variação e 1-0, para baixa variação. Posteriormente, realizou-se a somatória dos valores atribuídos a cada frequência declarada individualmente pelos professores para cada espaço ( 3 para uso semanal, 2 para várias vezes dentro do bimestre, 1 para uso 
eventual e 0 para nunca), cujo resultado foi divido pela somatória da quantidade de espaços utilizados, gerando assim, outro índice denominado índice de frequência de variação (IFV). As categorias estabelecidas para representação destes índices foram: 3 2,5 para variação semanal; 2,49 - 1,5 para variação várias vezes dentro do bimestre; 1,49 -0,5 para variação eventual e 0,49 - 0 para rara ou nenhuma variação. Os resultados apresentados geraram tabelas, que expressam resultados e discussões.

\section{Resultados e discussões}

Ao calcular o índice de frequência de uso dos espaços escolares para verificar quais são mais ou menos utilizados de acordo com as menções dos professores respondentes (gráfico 1), foi observado que o ambiente escolar declarado como mais usado pelos professores para as aulas de Ciências da Natureza é a sala de informática (IFU=2,1/CV=49\%), com sua frequência de utilização várias vezes no bimestre, ainda que não seja o ambiente declarado como o mais disponibilizado nas escolas. Entretanto, o coeficiente de variação alto indica que nem todos os professores pesquisados os utilizam com a mesma frequência. Gabini e Diniz (2012), ao realizar um trabalho com professores de uma escola estadual de Torrinha, em São Paulo, apresentaram um distanciamento dos dados em relação a esta pesquisa ao relatar a dificuldade ou resistência por parte dos educadores, de que os computadores sejam incorporados de fato às aulas de Ciências nos Anos Iniciais, aproveitando do potencial deste recurso a favor da aprendizagem dos alunos. Porém, afirmam que alguns professores já vêm utilizando a sala de informática de maneira mais frequente para atividades de consulta e busca por outros temas para trabalhar em sala de aula.

Um estudo realizado por Lopes et al. (2010) sobre o uso dos computadores em 400 escolas públicas do Ensino Fundamental e Médio de 12 capitais brasileiras apontou que mais $70 \%$ das escolas possuem laboratório de informática, de modo que $74 \%$ dos computadores disponíveis encontram-se no laboratório de informática e ainda, em 61\% das escolas, os professores fazem uso pedagógico do computador, principalmente quando assessorado pela presença de um professor especializado em Tecnologia da Informação e Comunicação (TIC).

Gráfico 1 - Índice de frequências de utilização (IFU) dos espaços escolares usados pelos professores nas aulas de Ciências dos Anos Iniciais do Ensino Fundamental. 


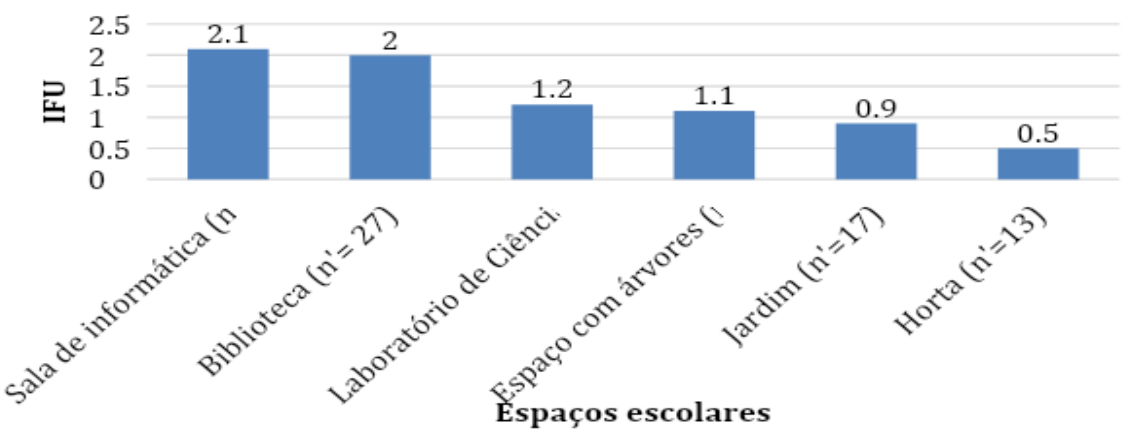

Fonte: Elaborado pelas autoras.

IFU = somatória dos valores atribuídos pela utilização ( 3 = utilização semanal, 2 = várias vezes dentro do bimestre, 1 = eventualmente e 0 = utilização rara ou não utilização) dividido por n'; n' = número de participantes da amostra, excluindo aqueles que declararam não haver o espaço escolar disponível.

0 espaço da biblioteca $(\mathrm{IFU}=2,0 / \mathrm{CV}=50 \%)$ é declarado pelos professores respondentes como o mais disponível e também usado várias vezes dentro do bimestre. Novamente, embora os dados apresentados indiquem a utilização várias vezes dentro do bimestre, o coeficiente de variação alto (CV), aponta que alguns professores utilizam esse espaço com uma frequência maior que outros. É importante salientar que, em algumas escolas que compuseram a amostra do município de São Bernardo do Campo (de acordo com contato da pesquisadora) o uso da biblioteca e da sala de informática é vinculado à grade horária de aulas semanais e, portanto, podem ser desenvolvidas atividades que contemplem as diferentes disciplinas. Isso pode favorecer o uso frequente desses ambientes. Enquanto em outras escolas, professores utilizam eventualmente. Ademais, a maior disponibilidade do espaço de biblioteca também pode estar associada ao Programa Nacional Biblioteca na Escola (PNBE), que tem como objetivo o fornecimento de obras e materiais de apoio à Educação Básica (FNDE, 2016).

Todos os outros espaços foram declarados como utilizados eventualmente pelos professores em frequências e disponibilidade variada.

Com relação ao laboratório de Ciências (IFU=1,2/CV=49\%), 84,8\% dos professores respondentes ( 28 de $n=33$ ) afirmam que as escolas não possuem esses espaços escolares disponíveis para a utilização, sendo que apenas uma das escolas que compõe a amostra disponibiliza e utiliza esse espaço para as aulas de Ciências. Estes dados dialogam com a pesquisa de Ramos e Rosa (2008), realizada com professores de dez escolas da região de Camapuã, em Mato Grosso de Sul. Tais autores relatam que a maioria dos professores discorda fortemente o fato de existirem laboratórios suficientes nas escolas para promoverem a experimentação. Esta não disponibilidade se remete, de modo geral, à necessidade de políticas públicas que invistam em escolas com melhor infraestrutura. 
Segundo Bomfim e Dias (2013), as escolas devem dispor de materiais e equipamentos de laboratório, pois, sua ausência é um dos principais fatores que dificultam a realização de atividades práticas.

Quanto aos espaços com árvores (IFU=1,1/CV=75\%), o índice de frequência de utilização aponta para sua utilização eventual, entretanto, ao coeficiente de variação alto mostra a dispersão dos dados em relação à média, assim, enquanto alguns professores indicam a utilização várias vezes no bimestre, outros nunca utilizam esse espaço. Sobre a frequência de utilização dos jardins declarada pelos professores respondentes (IFU= $0,9 / \mathrm{CV}=88 \%$ ) é possível observar que, assim como o uso de espaços com árvores, o coeficiente de variação indica se tratar de uma amostra heterogênea. No caso dos espaços de plantio ou horta (IFU=0,5/CV=112\%) esse também é declarado com a frequência de utilização eventual, tendo o coeficiente de variação alto apontando a heterogeneidade entre os respondentes. É importante considerar que os espaços de horta oferecem diversas possibilidades de trabalho voltadas ao ensino de Ciências da Natureza, buscando também promover modificações em hábitos alimentares para mais saudável e equilibrado; a percepção da necessidade de reaproveitamento de materiais recicláveis; 0 cultivo de hortaliças; a participação dos insetos no processo de polinização e o crescimento das plantas. Ademias, esse espaço também oferta a capacidade de trabalhar em equipe, cooperar, formar consciência cidadã, entre outros (ARAÚJO; DRAGO, 2011; CRIBB, 2010; REZENDE et al., 2014; SILVA; MUNARRETO; MANTOVANI, 2011; WEISSMANN, 1998).

É limitante que as escolas possuam poucos espaços para que as crianças possam ter o contato com a natureza. Uma área verde proporciona a oportunidade de vivenciar a natureza, estabelecendo conexões. Assim, a criança poderá estabelecer contato com pequenas plantas e animais e acompanhar mudanças na variação das estações do ano e da evolução natural (ELALI, 2003).

Sobre a frequência que os professores participantes de cada grupo declaram utilizar cada espaço (tabela 1), foram verificadas algumas semelhanças e diferenças. Quanto a biblioteca, independente do grupo, os professores utilizam 0 espaço preponderantemente várias vezes dentro do bimestre, com destaque inesperado para 0 grupo 3 (Grupo 1: IFU=1,82/CV=59\%; Grupo 2: IFU=1,83/CV= 72\%; Grupo 3: $\mathrm{IFU}=2,3 / \mathrm{CV}=29 \%$ ). Na realidade brasileira, a não disponibilidade do espaço não é sinônimo de não contato com os livros. As atividades podem ser realizadas pelos 
professores em sala de aula ou sala de leitura (CAMPELLO et al., 2018). Porém, de acordo com resultados do Sistema de Avaliação da Educação Básica (SAEB), a biblioteca é apontada como contribuinte para o bom desempenho dos alunos e já os Parâmetros Curriculares Nacionais (PCN) consideravam o espaço como fundamental para o desenvolvimento de programa de leitura eficiente e local de aprendizagem permanente (CAMPELLO et al., 2017). 0 quanto a biblioteca e outros fatores estão influenciando na aprendizagem do Grupo 3, merece ser foco de uma futura investigação qualitativa.

Os espaços com árvores são declarados como disponíveis e utilizados eventualmente pelos professores pertencentes aos três grupos (Grupo 1: IFU=1,20/CV=38\%; Grupo 2: IFU=1,33/CV=38\%; Grupo 3: IFU=0,5/CV=200\%), porém notou-se grande heterogeneidade de frequência de uso no grupo $3 \mathrm{com}$ alto CV. Na literatura, o uso pedagógico de locais arborizados da escola geralmente remete-se a Educação Infantil. Entretanto, sabemos da importância da continuidade do trabalho envolvendo esses espaços, principalmente em se tratando de atividades de observação e verificação, realizadas nas aulas de Ciências. De acordo com Elali (2003), o contato das crianças com a natureza permite estimular diversos sentidos, portanto, a escola deveria dispor de áreas com vegetação, areia, água, horta e até pequenos animais.

Tabela 1 - Índice de frequência de utilização (IFU) dos espaços escolares por grupo de participantes.

\begin{tabular}{|c|c|c|c|c|c|c|c|c|c|c|c|c|c|c|c|}
\hline \multirow[t]{2}{*}{ Espaços escolares } & \multicolumn{5}{|c|}{ Grupo $1(n=12)$} & \multicolumn{5}{|c|}{ Grupo 2(n=10) } & \multicolumn{5}{|c|}{ Grupo 3(n=11) } \\
\hline & IFU & $n^{\prime}$ & $n^{\prime \prime}$ & V & CV & $\mathrm{IFU}$ & $n^{\prime}$ & $n^{\prime \prime}$ & V & $\mathrm{CV}$ & $\mathrm{IFU}$ & $n^{\prime}$ & n" & V & CV \\
\hline Laboratório de Ciências & 1,20 & 5 & 4 & 0,70 & $70 \%$ & 0 & 0 & 0 & 0 & 0 & 0 & 0 & 0 & 0 & 0 \\
\hline Sala de informática & 1,89 & 9 & 8 & 1,71 & $69 \%$ & 0 & 1 & 1 & 0 & 0 & 2,50 & 10 & 9 & 0,28 & $21 \%$ \\
\hline Biblioteca & 1,82 & 11 & 10 & 1,16 & $59 \%$ & 1,83 & 6 & 5 & 1,77 & $72 \%$ & 2,30 & 10 & 9 & 0,46 & $29 \%$ \\
\hline Horta & 0,33 & 3 & 2 & 0,33 & $173 \%$ & 1,00 & 3 & 3 & 0 & 0 & 0,22 & 7 & 7 & 0,24 & $220 \%$ \\
\hline Jardim & 0,83 & 6 & 5 & 0,57 & $90 \%$ & 1,67 & 3 & 3 & 0,33 & $35 \%$ & 0,75 & 8 & 6 & 0,79 & $118 \%$ \\
\hline Espaço com árvores & 1,20 & 5 & 4 & 1,20 & $91 \%$ & 1,33 & 9 & 9 & 0,25 & $38 \%$ & 0,50 & 4 & 4 & 1 & $200 \%$ \\
\hline
\end{tabular}

Fonte: Elaborada pelas autoras

IFU= somatória dos valores atribuídos pela utilização, dividido n’; n'= número de participantes da amostra, excluindo aqueles que declaram não haver o recurso disponível; $n$ "= número de professores que afirmam usar ou não o recurso; V = variância e CV = coeficiente de variação. Categorias: Uso semanal (faixa de IFU=3-2,5); Uso várias vezes dentro do bimestre (faixa de IFU=2,49-1,5); Uso eventual (faixa de IFU=1,49-0,5); e não utilização ou rara utilização (faixa de IFU=0,49 - 0). 0 Grupo 1 é constituído por escolas com alto Ideb; o Grupo 2, com Ideb mediano e o Grupo 3, com escolas de baixo Ideb.

Considerando as diferenças apresentadas, é interessante notar que a sala de informática é o espaço mais disponibilizado e utilizado pelos professores do Grupo 3 (IFU=2,5/CV=21\%), com o coeficiente de variação baixo mostrando homogeneidade nas respostas. Há diferentes possibilidades a serem investigadas, que talvez expliquem o fato 
das escolas com baixo Ideb terem mais professores que dizem utilizar a sala de informática. Talvez as salas de informática possam indicar um investimento em escolas com baixo rendimento na tentativa de reverter os índices. Outra possibilidade, é que apesar dos professores usarem o ambiente, outras carências impedem que essa utilização realmente influencie na aprendizagem do aluno. De acordo com Lopes et al. (2010), problemas com infraestruturas são apontados com maior frequência em escolas das regiões Norte, Nordeste e Centro-Oeste, fator que contradiz os dados apresentados nessa pesquisa, pois, as escolas pesquisadas pertencem ao Grupo 3, pertencem em maior número à região Nordeste, entretanto pode justificar o IFU=0 apresentado pelo Grupo 2 (com duas escolas também pertencentes a região Nordeste). 0 IFU 1,89\% apresentado pelo Grupo 1, pode ser justificado pela falta de professores em informática educativa principalmente na região Sul e Sudeste, conforme os estudos citados anteriormente.

O laboratório de Ciências é um espaço disponibilizado e utilizado apenas por uma escola do Grupo 1 (IFU=1,2/CV=70\%). De acordo com os professores pesquisados, este espaço é pouco disponibilizado nas escolas ( 1 de $\mathrm{N}=9$ ). Entretanto, quando disponibilizado, os professores geralmente fazem uso eventual do local (apesar de termos uma amostra heterogênea segundo o CV). É importante que pesquisas futuras se debrucem em investigar como esses laboratórios são utilizados pelos professores polivalentes dos Anos Iniciais do Ensino Fundamental. Alguns fatores foram apontados por Borges (2002) para a não utilização do laboratório e equipamentos por professores do Ensino Fundamental e Médio, entre eles podemos citar: laboratório fechado e sem manutenção; questões relacionadas à carência de atividades preparadas para que o professor possa usar; a falta de recursos financeiro disponível para compra de materiais e componentes de reposição e a falta de tempo para o planejamento do professor na realização de atividades. Essas razões também são apontadas quando ao uso dos computadores nas escolas.

O espaço da horta é mencionado como mais disponível aos professores pertencentes ao Grupo 3, entretanto, a frequência de utilização apontada é maior entre os professores de Grupo 2 (IFU=1,0), com respostas homogêneas ( $C V=0)$. No Grupo 1 (IFU=0,33/CV=173\%), o IFU (IFU=0,33) indica que o espaço é raramente utilizado, porém com alta da média ( $\mathrm{CV}=173 \%)$ sinalizando diferentes frequências de uso entre os docentes. Um melhor aproveitamento desse espaço poderia proporcionar uma maneira diferente de ensinar conteúdos curriculares do ensino de Ciências, principalmente 
associado à alimentação saudável. Além disso, possibilita uma prática fundamentada, dispondo de fatos reais que possibilitam a aprendizagem com significado (FERNANDES, 2005).

Sobre a quantidade de espaços escolares mencionados como utilizados pelos professores (tabela 2), na declaração da maioria dos docentes $(60,6 \%)$ sinaliza que realizam uma média variação, alterando suas aulas em 2 ou 3 desses espaços. Entretanto, é possível perceber que os professores pertencentes ao Grupo 3 mencionam diversificar um pouco mais suas aulas, pois, aproximadamente $90 \%$ deles ( 9 de $n=11)$ utilizam mais do que um espaço além da sala de aula, sendo grande parte, entre 2 e 3 espaços (81,9\%). Nos Grupos 1 e 2, há maiores semelhanças entre os resultados apresentados.

Tabela 2 - Quantidade de espaços escolares mencionados como utilizados pelos professores participantes dos Anos Iniciais do Ensino Fundamental para o ensino de Ciências Naturais (excluindo sala de aula).

\begin{tabular}{lccccccccc}
\hline & \multicolumn{3}{c}{ Grupo 1 $(\mathbf{n = 1 2})$} & \multicolumn{2}{c}{ Grupo 2 $(\mathbf{n = 1 0})$} & \multicolumn{2}{c}{ Grupo 3 (n=11) } & \multicolumn{2}{c}{ Total } \\
\hline Categorias & QEE & nPR & \%PR & nPR & \%PR & nPR & \%PR & nPR & $\%$ PR \\
\hline Alta Variação & $4-5$ & 2 & 16,7 & 1 & 10 & 1 & 9 & 4 & 12,1 \\
Média Variação & $2-3$ & 6 & 50 & 5 & 50 & 9 & 81,9 & 20 & 60,6 \\
Baixa Variação & $0-1$ & 4 & 33,3 & 4 & 40 & 1 & 9 & 9 & 27,3 \\
\hline & Total & 12 & 100 & 10 & 100 & 11 & 100 & 33 & 100
\end{tabular}

Fonte: Elaborada pelas autoras.

$\mathrm{QEE}=$ quantidade de espaços escolares mencionados pelos professores; $\mathrm{nPR}=$ número de professores respondentes; \%PR = porcentagem de professores respondentes.

A diversificação de espaços possibilita o desenvolvimento de práticas pluralistas. De acordo com Laburú, Arruda e Nardi (2003), um professor pluralista deve se arriscar, inovar, experimentar e explorar diferentes possibilidades de inovação didática, buscando soluções criativas a favor da qualidade da aprendizagem e do saber do aluno. A variação dos espaços escolares possibilita o desenvolvimento de diferentes procedimentos metodológicos que poderá atingir alunos que variam em sua motivação, preferência, estilo e modo de aprender, além de eliminar o tédio da sala de aula.

Os dados expressos na tabela 3 mostram o índice de frequência de variação de espaços declarados como utilizados individualmente pelos professores. Entre os professores pesquisados, é possível verificar que mais da metade declara variar a utilização dos espaços escolares várias vezes dentro do bimestre (18 de $n=33$ ). Entretanto, novamente, analisando comparativamente as frequências, é possível perceber que os professores pertencentes ao Grupo 3 mencionam variar ainda mais, contrariando ao esperado. Deles, $36,4 \%$ utilizam mencionam variar semanalmente de espaço ( 4 de $n=11$ ) 
e ainda $54,5 \%$ preponderantemente várias vezes no bimestre (6 de $n=11$ ). Todavia, o coeficiente de variação alto (na grande maioria dos professores superior a $50 \%$ ) indica que os professores utilizam alguns espaços com uma maior frequência que outros, mostrando uma heterogeneidade entre as respostas. Apenas um professor do Grupo 1 (1 de $n=12$ ) e outro do Grupo 3 ( 1 de $n=11$ ) dizem não variar o espaço de suas aulas para 0 ensino de Ciências da Natureza, utilizando apenas o espaço da sala de aula convencional.

Tabela 3 - Índice de frequência de variação (IFV) de espaços escolares por professores polivalentes nas aulas de Ciências nos Anos Iniciais do Ensino Fundamental.

\begin{tabular}{l|c|cc|cc|cc|cc}
\hline & & \multicolumn{2}{|c|}{ Grupo 1 $(\mathrm{n}=12)$} & \multicolumn{2}{c|}{ Grupo 2 (n=10) } & \multicolumn{2}{c|}{ Grupo3 (n=11) } & \multicolumn{2}{c}{ Total } \\
\hline Frequência & $\mathrm{IFV}$ & $\mathrm{nPR}$ & $\% \mathrm{PR}$ & $\mathrm{nPR}$ & $\% \mathrm{PR}$ & $\mathrm{nPR}$ & $\% \mathrm{PR}$ & $\mathrm{nPR}$ & $\% \mathrm{PR}$ \\
\hline Semanal & $2,5-3$ & 1 & 8,3 & 0 & 0 & 4 & 36,4 & 5 & 15,1 \\
Várias vezes no bimestre & $1,5-2,49$ & 6 & 50 & 6 & 60 & 6 & 54,5 & 18 & 54,6 \\
Eventual & $0,5-1,49$ & 4 & 33,3 & 4 & 40 & 0 & 0 & 8 & 24,3 \\
Nunca & $0-0,49$ & 1 & 8,3 & 0 & 0 & 1 & 9,1 & 2 & 6 \\
\hline & Total & 12 & 100 & 10 & 100 & 11 & 100 & 33 & 100
\end{tabular}

Fonte: Elaborada pelas autoras

IFV = índice de frequência de variação= somatória da frequência de utilização segundo os professores respondentes e dividido pela quantidade de espaços que alegam utilizar. $0 \mathrm{nPR}=$ número de professores respondentes; \%PR = porcentagem de professores respondentes. Categorias: variação semanal (3-2,5); várias vezes dentro do bimestre (2,49-1,5); variação eventual $(1,49-0,5)$; e $(0,49-0)$ para não variação ou rara variação. 0 Grupo 1 é constituído por escolas com alto Ideb; 0 Grupo 2, com Ideb mediano e o Grupo 3, com escolas de baixo Ideb.

De modo geral, os professores das escolas com Ideb mais baixo declaram variar os espaços utilizados com maior frequência do que os professores pertencentes aos outros dois grupos. Porém, é preciso investir em novas pesquisas qualitativas que busquem compreender esse fenômeno, a natureza das propostas desenvolvidas nesses espaços.

Por fim, os professores envolvidos nesta pesquisa responderam que entre os fatores que os levam a pouco utilizar certos recursos, procedimentos didáticos e espaços escolares estão, além da disponibilidade, a falta de tempo para planejar, separar os materiais e trabalhar com a disciplina, devido à grade escolar; além da sensação de falta de preparação/formação para trabalhar Ciências da Natureza (BUENO, 2017). Tempo, portanto, parece ser um fator fundamental para a diversificação do uso de recursos, procedimentos didáticos e espaços.

\section{Conclusões e considerações finais}


Os dados aqui apresentados são importantes, pois os trabalhos disponíveis na literatura há uma carência de investigações relacionadas à utilização de variados espaços. As pesquisas que tratam da possibilidade de utilização dos espaços escolares, geralmente, estão atreladas à investigação específica de um determinado espaço, como por exemplo, o espaço de horta ou o laboratório de Ciências. Também se notou que muitos dos relatos estão vinculados a experiências realizadas em escolas específicas, em um contexto restrito, geralmente descrevendo trabalhos realizados nesses espaços.

Havia, portanto, uma carência de compreensão sobre como os professores transitavam nos diferentes espaços escolares para ensinar Ciências, especialmente quando presentes na escola. Essa pesquisa visa não responder tudo, mas tentou sanar parte dessa lacuna, buscando apresentar dados empíricos, que mostrassem a frequência de uso de outros espaços escolares, além da sala de aula, segundo a declaração de professores atuantes de escolas públicas, com enfoque nas aulas de Ciências da Natureza.

Assim, concluímos que espaços como a sala de informática e a biblioteca foram mencionados como mais frequentemente usados pelos professores pesquisados, e também os mais disponíveis. A utilização da sala de informática pode estar vinculada à utilização de recursos didáticos como computadores, netbooks e tabletes, mostrando que o uso das tecnologias está cada vez mais frequente nas aulas de Ciências da Natureza, apesar de não atingir a maioria nacional (INEP, 2017). A disponibilidade e utilização do espaço da biblioteca podem ser favorecidas por programas educacionais, como o Programa Nacional Biblioteca na Escola (PNBE) que possibilitou a ampliação dos acervos escolares. Nas bibliotecas é possível estar disponível recursos impressos (livros didáticos, livros paradidáticos ou de literatura-infantil, jornais e revistas), audiovisuais (televisão, DVD, CDs de música e vídeos), entre outros (FNDE, 2016). Segundo nossos próprios dados, esses recursos didáticos também foram mencionados como mais utilizados pelos professores (BUENO, 2017). Assim, quando os professores têm acesso a esses espaços, geralmente os utilizam várias vezes dentro do bimestre para o ensino de Ciências.

Entretanto, e os espaços verdes (espaços com árvores, hortas e jardins) e principalmente os laboratórios de Ciências estão entre os menos disponíveis e menos utilizados. Diante dessa observação, vários questionamentos podem surgir. Estaria a disponibilização do espaço ajudando a promover uma cultura de utilização pelos docentes? Há mais políticas ou práticas de formação de professores que estejam atreladas utilização dos espaços mais disponíveis? 0 fato de serem ambientes que atendem de forma 
mais explicita às necessidades de várias disciplinas estaria levando a uma maior aproximação dos professores a esses espaços? Há nas escolas profissionais que auxiliam o professor no uso desses ambientes e por isso tornam sua utilização viável? Em nossa experiência cotidiana, temos exemplos de escolas públicas onde há profissionais responsáveis pelas bibliotecas e ou salas de informática. Resta saber o quanto esse tipo de apoio atinge todas as escolas. Portanto, diante dos dados obtidos por essa pesquisa, surgem novos questionamentos em torno das reais razões sobre a frequência de utilização desses ambientes. Novas pesquisas são importantes para aprofundar a compreensão da complexidade dessa realidade.

Com relação ao uso do laboratório de Ciências, Weissmann (1998) declara que a ausência ou existência dos espaços de laboratório, dentro ou fora da sala de aula, dizem muito sobre a importância que se é dada às ciências dentro do currículo escolar e também a sua abordagem didática entre os envolvidos no processo de ensino e aprendizagem. Mesmo quando presente, esse espaço foi relatado como eventualmente utilizado. Algo similar também foi visto com os espaços que envolvem a natureza, como: espaços com árvores, jardim e horta. As expectativas e investimentos em torno do ensino de Ciências da Natureza são sempre menores, iniciando pela valorização do ensino da Língua Portuguesa, nas avaliações de larga escala (GARCIA et al., 2018).

Pesquisas mostram que os professores se sentem despreparados para ensinar Ciências da Natureza (AUGUSTO; AMARAL, 2015; LANGHI; NARDI, 2005; LONGHINI, 2008) e experimentação (RAMOS; ROSA, 2008), o que pode influenciar na utilização apenas eventual dos espaços verdes e laboratórios, quando disponibilizados, já que seu uso envolve observação de fenômenos e investigações. Propostas formativas de integração de atividades ao processo de alfabetização, geralmente apenas destinado à disciplina Língua Portuguesa, possibilita mais tempo para trabalhar Ciências. A construção de pequenos registros escritos dos fenômenos observados na horta da escola ou no jardim, por exemplo, auxiliam o desenvolvimento de habilidades não somente pertencente ao ensino de Ciências, mas também à escrita. Dados coletados podem ser quantificados, classificados e graficados, possibilitando propiciando habilidades matemáticas.

Nessa perspectiva, a compreensão sobre a prática docente é importante para identificar a necessidade de intervenções e transformações. Esses que podem ser financeiros, em relação à construção de alguns espaços escolares e a disponibilidade dos 
materiais. Acredita-se, por exemplo, na importância de investir em laboratórios de Ciências nas escolas dos Anos Iniciais do Ensino Fundamental, dispondo ao menos de carteiras para que os alunos possam trabalhar em grupos, uma pia e outros materiais que possam ser utilizados em diferentes experimentos. Um ambiente que não requer tantos equipamentos e vidrarias, mas que facilite a realização de atividades experimentais e investigativas.

Além disso, o investimento pode partir de políticas para melhoria das condições de trabalho dos professores, podemos incluir discussões sobre a questão da importância da redução do número de alunos por turma para viabilizar a gerência das atividades e do aumento de tempo para planejamento das aulas e organização dos espaços antes e depois das atividades, pois, devemos levar em consideração, por exemplo, que preparar o laboratório para uma experimentação, ou construir uma horta, demanda um tempo maior para planejar e organizar.

Por fim, o conhecimento sobre a prática dos professores possibilita reflexões e ações que visem à melhoria na qualidade de ensino e aprendizagem dos alunos, as quais envolvem, mas não se restringe a formação docente. Devem também incluir políticas públicas e investimentos voltados às condições de trabalhos dos professores.

\section{Referências}

ARAÚJO, M.P.M.; DRAGO, R. Projeto Horta: a mediação escolar promovendo hábitos alimentares. Revista FACEV, Vila Velha, n. 6, p. 126-139, 2011.

AUGUSTO, T. G. S.; AMARAL, I. A. A formação de professoras para o ensino de ciências nas séries iniciais: análise dos efeitos de uma proposta inovadora. Ciência \& Educação, Bauru, v. 21, n. 2, p. 493-509, 2015.

BORGES, A. T. Novos rumos para o laboratório escolar de ciências. Caderno Brasileiro de Ensino de Física, Florianópolis, v. 19, n. 3, p. 291-313, 2002.

BOMFIM, G. F.; DIAS, V. B. Aulas de Ciências Naturais em escolas de Ensino Fundamental I: relações existentes entre a estrutura física dos laboratórios e a realização de atividades experimentais. In: ENCONTRO NACIONAL DE PESQUISA EM EDUCAÇÃO EM CIÊNCIAS, 9., Águas de Lindóia, 2013. Anais...São Paulo: EMPEC, 2013.

BUENO, K. C. A utilização de recursos, procedimentos e espaços escolares nas aulas de ciências naturais dos anos iniciais de Ensino Fundamental. 2017. Dissertação (Mestrado em Ensino, História das Ciências e da Matemática) - Universidade Federal do ABC, Santo André, 2017.

CAMPELLO, B.; CARVALHO, M. C.; ANDRADE, M. E. A.; VIANNA, M. M.; CALDEIRA, P. T.; ABREU, V. L. F. G. A biblioteca escolar: temas para uma prática pedagógica. Autêntica, 2017. 
CAMPELLO, B.; REZENDE, M. E. P.; VIANNA, M. M.; CALDEIRA, P. T.; MACEDO, V. A. A.; ABREU, V. L. F. G. Como usar a biblioteca na escola: um programa de atividades para o ensino fundamental. Autêntica, 2018.

CRIBB, S. L. S. P. Contribuições da educação ambiental e a horta escolar na promoção de melhorias ao ensino, à saúde e ao ambiente. REMPEC - Ensino, Saúde e Ambiente, Niteroi v. 3, n. 1, p. 42-60, 2010.

ELALI, G. A. O ambiente da escola: o ambiente na escola. São Paulo: Portal educação, 2003.

FERNANDES, M. C. A. A horta escolar como eixo gerador de dinâmicas comunitárias, educação ambiental e alimentação saudável e sustentável. Revista Ciências Exatas e Tecnológicas, Londrina, v. 9, n. 9, p. 37-45, 2005.

FNDE - FUNDO NACIONAL DE DESENVOLVIMENTO DA EDUCAÇÃO. Apresentação. Brasília: FNDE, 2016. Disponível em: http://www.fnde.gov.br/programas/biblioteca-daescola/biblioteca-da-escola-apresentacao. Acesso em: 20 mar. 2017.

GABINI, W. S.; DINIZ, R. E. S. A formação continuada, o uso do computador e as aulas de Ciências nos Anos Iniciais do Ensino Fundamental. Revista Ensaio, Belo Horizonte, v. 14, n. 33, p. 333-348, 2012.

GARCIA, P. S.; FAZIO, X.; PANIZZON, D.; BIZZO, N. Austrália, Brasil e Canadá: impacto das avaliações no ensino de Ciências. Estudos em Avaliação Educacional, São Paulo, v. 29, n. 70, p. 188-221, 2018.

GOMES, A.; RÉGIS, A. Desempenho e infraestrutura: mapeamento das escolas públicas da região metropolitana do Rio de Janeiro. In: CONGRESSO IBERO AMERICANO DE POLÍTICA E ADMINISTRAÇÃO DA EDUCAÇÃO, 3., Zaragoza, 2012. Anais [...]. Zaragoza: [s. n.], 2012.

GRAÇA, P.; BERNARDES, L.; SANTANA, M. Biblioteca escolar: curso técnico de formação para os funcionários da educação. Brasília: Universidade de Brasília, 2007. Disponível em: http:portal.mec.gov.br/seb/arquivos/pdf/profunc/biblio_esc.pdf. Acesso em: 16 abr. 2017.

HOFSTEIN, A.; LUNETTA, V. N. The role of the laboratory in science teaching: neglected aspects of research. Review of Educational Research, Washington, v. 52, n. 2, p. 201-217, 1982.

HOFSTEIN, A.; LUNETTA, V. N. The laboratory in science education: foundations for the twenty-first century. Science education, Salem, v. 88, n. 1, p. 28-54, 2004.

INEP - INSTITUTO NACIONAL DE ESTUDOS E PESQUISAS EDUCACIONAIS ANÍSIO TEIXEIRA. Nota estatística: censo escolar da educação básica. Brasília: INEP: Ministério da Educação, 2017. Disponível em: http://portal.inep.gov.br/sinopses-estatisticas-da-educacao-basica. Acesso em: 25 abr. 2017.

JACOBUCCI, D. F. C. Contribuições dos espaços não-formais de educação para a formação de cultura cientifica. Em extensão, Uberlândia, v. 7, n. 1, p. 55-66, 2008.

LABURÚ, C. E; ARRUDA, S. M.; NARDI, R. Pluralismo metodológico no ensino de ciências. Ciência e Educação, Viçosa, v. 9, n. 2, p. 247-260, 2003.

LOPES, R. D. et al. O uso dos computadores e da internet em escolas públicas de capitais brasileiras. Estudos \& Pesquisas Educacionais, São Paulo, n. 1, p. 275-335, 2010. 
LANGHI, R.; NARDI; R. Dificuldades de professores dos anos iniciais do ensino fundamental em relação ao ensino da astronomia. Revista Latino-Americana de Educação em Astronomia RELEA, São Carlos, n. 2, p. 75-92, 2005.

LONGHINI, M. D. O conhecimento do conteúdo científico e a formação do professor das séries iniciais do Ensino Fundamental. Investigações em Ensino de Ciências, Porto Alegre, v. 13, n. 2, p.241-253, 2008.

MORAN, J. M. Os novos espaços de atuação do professor com as tecnologias. Revista Diálogo Educacional, Curitiba, v. 4, n. 12, p. 13-21, 2004.

NAKAMURA, H. K.; BERNARDI, N. S.; LAMIN-GUEDES, V. 0 trabalho em campo em jardins escolares. Revista Educação Ambiental em Ação, [S. l.], v. 11, n. 42, 2012. Disponível em: http://www.revistaez.org/pdf.php?idartigo=1391. Acesso em: 7 set. 2016.

NÓVOA, A. Para uma análise das instituições educacionais as organizações escolares em análise. [Lisboa]: Instituto de Inovação Educacional, 2011. (Temas de Educação 2).

PATTON, M. Q. Qualitative evaluation and research methods. Newbury Park: Sage Publication, 1990.

RAMOS, L. B.; ROSA, P. R. S. 0 ensino de ciências: fatores intrínsecos e extrínseco que limitam a realização de atividades experimentais pelo professor dos Anos Iniciais do Ensino Fundamental. Investigações em Ensino de Ciências, Porto Alegre, v. 13, n. 3, p. 299-331, 2008.

REZENDE, B. L. A.; ALMEIDA, J. S.; AMADO, M. V.; PEREIRA, M. R.; CARVALHO, V. S.; ENDRINGER, D. C; LEITE, S. Q. M. A interdisciplinaridade por meio da pedagogia de projetos: uma análise do projeto "Horta escolar: aprenda cultivando hortaliças" numa perspectiva CTSA. Revista Eletrônica Debates em Educação científica e Tecnológica, Vitória, v. 4, n. 1, p. 179-191, 2014.

SÁTYRO, N. G. D.; SOARES, D. S. A infraestrutura das escolas brasileiras de ensino fundamental: um estudo com base nos Censos Escolares de 1997 a 2005. Brasília: Ipea, 2007.

SILVA, C. T. A. C.; MUNARETTO, F. C.; MANTOVANI, T. Viabilidade na utilização da horta da escola como laboratório para o ensino de Ciências e Biologia. Revista Didática Sistêmica, Rio Grande, v. 13, n. 1, p. 50-63, 2011.

SOARES NETO, J. J.; JESUS, G. R.; KARINO, C. A.; ANDRADE, D. F. Uma escala para medir a infraestrutura escolar. Rev. Est. Aval. Edu., São Paulo, v. 24, n. 54, p. 78-99, 2013 a.

SOARES NETO, J. J.;.KARINO, C. A.; JESUS, G. R.; ANDRADE, D. F. A infraestrutura das escolas públicas brasileiras de pequeno porte. Revista do Servidor público, Brasília, v. 64, n. 3, p. 377391, 2013b.

WARD, H.; RODEN, J.; HEWLETT, C.; FOREMAN, J. Ensino de ciências. Porto Alegre: Artmed, 2010.

WEISSMANN, H. Didática das ciências naturais. contribuições e reflexões. Porto Alegre: Artmed, 1998. 